\title{
Research on Urban Sports Education Problems and Its Countermeasures
}

\author{
Fenshan Liu $^{1}$ \\ ${ }^{1}$ P.E Department YuLin University, Shanxi, 719000 \\ 43967125@163.com
}

Keywords: Urban Sports Education; Problems and Solutions; Teens

\begin{abstract}
In the process of Chinese economic transformation and upgrading, the city needs a new economic growth point, with the features of green industry, the sports industry has great development value. How to develop China's urban sports industry has become one of the hot topics at this stage of the sports world. This paper analyzes the development of sports in China's urban education problems and proposes countermeasures on the development of urban physical education.
\end{abstract}

\section{Introduction}

With the development of the sports industry, it is the world's economic and social development, improving people's living standards, increased leisure time in the 1960s and developed. After the 1970s, due to the development of science and technology, to further promote the development of sports industry, thereby enhancing the vitality of the development of the sports industry in the 1980s, the development of sports industry has entered an unprecedented peak of its influence in the global scope internal expansion. It was at this time, with the rapid development of the implementation of China's opening up and economic and social development, the concept of the sports industry also entered our field of vision, it is both the product of sports in our country under the new historical conditions for development, but also people understanding of the nature of the sports authorities produce results deepen. Sport is an industry that recognizes this basic research is the cornerstone of sports economy. However, since the sports economist States, sports industry experts, sports sociologists, each in different research angles, different research positions, different research purposes, different social backgrounds, thus put forward their alien Sports industry science point of view, and gives a different concept.

\section{Physical Education in the Present}

Generally speaking, at present in our country, sports education neither paying sufficient attention to schools and education administration, did not lead to sufficient concern the family and society and in academic research is basically in its infancy state. The reason there are basically two: First, because the adult overall general lack of awareness of sports participation, so the importance and necessity of physical education naturally can not pay attention. Secondly, the current education system, due to the presence of various problems on education concepts and education system, results in physical education, especially small people lack plaque. On the concepts of education, there are a lot of people believe that today's children are in the rack their brains to play every day, have been quick to play crazy, and seriously affected the study. That is now "played" and if then the physical education would be "disastrous consequences." In the education system, "examination-oriented education" don’t allow people to "play", teachers and parents fear that people can not "study hard." All of these are a direct result of the quality of contemporary teen life sports seriously low. According to a survey the National Work Committee Office and the China Youth Research Center in 1999 for the children's development and in 2005 made another comparison of the findings of this survey tracks made by the current living conditions of our young people in general are: 
(1) Less time and be deprived. Findings in 1999 and 2005, on the one hand people eager to get independent living, on the one hand from the academic burden on schools, "much hope" from their parents but also greatly limits the people's autonomy.

(2) The lack of a small partner, parents when playmates. The survey found that parents often or sometimes recreational activities together have 48.8 percent of the small people, there are more than $10 \%$ of children choose the "most willing to play." Obviously, both of which have a negative impact on adolescent mental health and good character will develop.

(3) Lack of outdoor sports activities. Survey results showed that adolescent outdoor sports activities seriously understaffed, due to the lack of places in addition to the game, the parents of obstruction is one very important reason. 17.5 percent of people said, "In order to more study time, parents often let me to outdoor activities", 24.2\% choose "Sometimes." There are 16.6\% of people answered "sometimes or often frustrate parents and small partners to play with me. For adolescents is concerned, the adverse consequences arising from lack of physical education are obvious. First, the lack of physical education will affect the youth healthy growth Suhomlinski famous educator said:"Education is the source of intellectual life, and make young people onto the road of scientific think and it is an important condition for personality development. Only when the child according to their wishes free to use 5-7 hours of free time each day, be possible to develop a smart all-round development of people. Leave it to talk about comprehensive development, talk about the quality culture hobby, natural talents, just an empty phrase has been.

Secondly, the lack of youth sports education will directly affect the quality of life to their full adult. The fact that young people grow up without freedom of living environment, their sense of autonomy and choice will gradually disappear, and so its direct consequence is that once they become adults, the face of a lot of time will be due to not have their own hobbies and interests and helpless, I do not know what to do do. Freshmen year performance clearly proves this point. With the tight end and adults live starting high school life in the face of relatively more free time on campus life, many people will feel bored and empty, which is why, like to indulge in some unhealthy way networks or love boredom spread phenomenon in the current university campus reason.

The lack of a small partner, parents when playmates. The survey found that parents often or sometimes recreational activities together have 48.8 percent of the small people, there are more than $10 \%$ of children choose the "most willing himself to play." Obviously, both of which have a negative impact on adolescent mental health and good character will develop.

Outdoor Sports insufficient. Survey results showed that adolescent outdoor sports activities seriously understaffed, due to the lack of places in addition to the game, the parents of obstruction is one very important reason. 17.5 percent of people said that to learn a little more time, parents often let me to outdoor activities, $24.2 \%$ choose "Sometimes." There are $16.6 \%$ of people answered "sometimes or often frustrate parents and small partners to play with me. For adolescents is concerned, the adverse consequences arising from lack of physical education are obvious. First, the lack of physical education will affect the youth healthy growth Suhomlinski famous educator said: "Education is the source of intellectual life, and makes young people onto the road of scientific think and it is an important condition for personality development. Only when the child according to their wishes free to use 5-7 hours of free time each day, be possible to develop a smart all-round development of people. Leave it to talk about comprehensive development, talk about the quality culture hobby, natural talents, just an empty phrase has been. "Secondly, the lack of youth sports education will directly affect the quality of life to their full adult. The fact that there is no freedom of adolescents living environment to grow, their sense of autonomy and choice will gradually disappear, which is a direct consequence of a long wait for them once Great for adults, and face a lot of time will be due to not have their own hobbies and interests and helpless, do not know how do we go every year freshmen's performance clearly proves this point. With the end of high school life tension and adults live beginning, faced relatively more free time on campus life, many people will feel bored and empty, which is why, like to indulge in some unhealthy way networks or boredom love phenomenon in the current university campus the spread of the reason why. 


\section{Chinese Urban Development Goals and Strategies of Physical Education}

Use various channels to enhance physical education. People in our small city at the beginning of the implementation of physical education, we should first make use of multi-media presentations and a variety of sports channels to strengthen publicity and education, improve the faculty, parents, and educational administrators sports consciousness, so that they are physical education and in life the importance of understanding, to promote as many people to support and get involved. For people to engage in sports activities, school sports curriculum set up to provide a good environment for development. Propaganda work of physical education is to promote the implementation of the urban petty people work an important part of physical education.

Government should give policy guidance and financial support. In the process of implementation in physical education, policy support and financial security is essential. Policy is an important basis for the implementation of physical education, financial investment is an important material guarantee good sport education. By actively Theory and Practice of Physical Education, demonstrating the effect and importance of physical education, for the attention of the relevant government departments at all levels to gradually introduce the corresponding guide and strengthen the school physical education policies of related increase Physical education finance and energy inputs. Create a virtuous cycle of small people Physical Education.

School of Physical Education and form mutually beneficial business units sustainable development. When companies cooperate with school physical education, schools can use their own talents and physical education sports training venues for the business units, in exchange for enterprises to continue to provide material support to the development of school physical education, the formation of mutually beneficial sustainable development. It can also attract business into the school sports talent, strengthening of interaction between enterprises and schools. To do so, on the one hand, through cooperation with the business units, you can get support and additional funding on schools is conducive to better carry out physical education activities; Furthermore, through the interaction between schools and enterprises can expand a small to a certain extent extensive contacts with people and society, to better promote their social development.

Give full play to the role of the main positions in physical education in schools. Schools at all levels should develop a high degree to understand the significance of the new century to carry out physical education. Take various measures, so that people from thinking sports really recognize the importance of their full development, which gradually establish a correct sports consciousness. Through physical education, train people to develop a reasonable and beneficial habit, learn to reasonable control and use their own time, to raise awareness of self-planning time, self-judgment, the ability to self-evaluation, arouse people to use sports activities to improve the quality of life awareness, raise their awareness of the educational value of sport. The goal is to determine when we implement physical education. We must first solve a fundamental problem. Target in the development of school education, in addition to let people acquire the necessary knowledge, skills through learning, but also enable them to acquire knowledge, skills and techniques of sports, so that they can not only acquire knowledge, learn to create, but you can learn, learn life. Therefore, a clear position of physical education in school education is very necessary, but also the implementation of quality education requires.

Focus on physical education in science, system studies, establishment of China's national conditions suitable for the city with little people Physical Education. Any work has its inherent laws and requirements. Little people physical education is no exception. To improve the effectiveness of the small people of the city to implement physical education, we should seriously explore the development of the law in which to identify the most suitable for China's sports education pathway or mode. This requires China's relevant scholars and theorists can be combined with the actual conditions of China, the model based "School-Family Community" on the Trinity, to explore and establish a more comprehensive, systematic, operability stronger physical education mode. The implementation of this model should not only reflect a wide range of sports and prominent freedom, personal property, the main features, but also demonstrate the excellent level of values and 
civilization of the Chinese nation, and ultimately to help promote socialist spiritual civilization, improve quality of life, the purpose of training qualified personnel socialism.

\section{Conclusion}

In a word, the countermeasures to enhance the development of urban physical are: use various channels to enhance physical education advocacy, to guide social institutions to actively participate in physical education, government should give policy guidance and financial support, the formation of school physical education and business units of mutual benefit and sustainable development. Enhance physical education instructor training, to build a sufficient quantity, quality high enough physical education teachers. Give full play to the role of the main positions in physical education in schools. Focus on physical education in science, system studies, establishment of China's national conditions suitable for the city with little people Physical Education.

\section{References}

[1] Su Hua. Situation and Development of Olympics Sports Industry in Jiangxi Province. Market Modernization, 2009 (14).

[2] Shen Xinyu. Current Situation of Sports Industry in China and the Sustainable Development Strategy. Exam Week, 2010 (05).

[3] Zhou Bo. The Sports Industry Development and Urban Modernization. Market Modernization, 2011 (01).

[4] Chang Jing. Present Situation of Sports Industry and Recommendations on Its Accession to the WTO after Several Development.2006 Hubei Sports Science (1): 1-3. 